
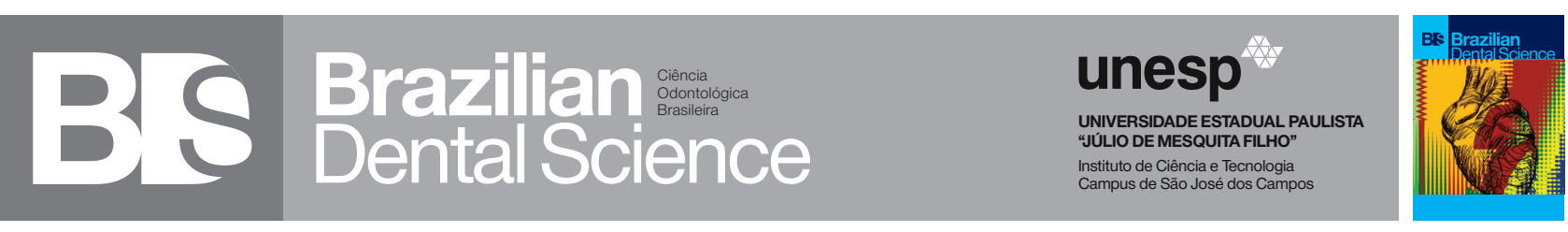

\title{
(i)
}

\section{Prefabricated composite resin veneers: a clinical case report}

Facetas pré-fabricadas em resina composta: relato de caso

\author{
Amanda Oliveira de ARAÚJO무 , Davi Farias MANTA ${ }^{1}$, Mário José Pinto LOPES ${ }^{2}$, Marlus da Silva PEDROSA³, Claudio Heliomar Vicente \\ da SILVA ${ }^{4}$, Márcia de Almeida DURÃO ${ }^{5}$ \\ 1 - Department of Dentistry - Centro Universitário Maurício de Nassau - UNINASSAU - Recife - PE - Brazil. \\ 2 - Department of Post-graduation in Dentistry - Centro de Pós-Graduação em Odontologia Faculdade Sete Lagoas - Recife - PE - Brazil. \\ 3 - Department of Dentistry - Faculdade Integral Diferencial - DeVry | Facid - Teresina - PI - Brazil. \\ 4 - Department of Prosthetic Dentistry and Maxillofacial Surgery - Federal University of Pernambuco - UFPE - Brazil. \\ 5 - Centro Universitário Maurício de Nassau - UNINASSAU - Recife - PE - Brasil.
}

\begin{abstract}
The authors present a complete clinical case report of functional and aesthetic rehabilitation of the smile harmony of a 23-year-old male patient through periodontal plastic surgery, tooth bleaching and prefabricated composite resin veneers, emphasizing the advantages, limitations and patient's perceptions about the treatment. After clinical and radiographic evaluations, extra and intra-oral photographs were taken, plaster study models were obtained, digital smile design and diagnostic wax-up were performed. The patient accepted and authorized the proposed dental procedures. The treatment proved to be effective, being a practical and safe approach, with aesthetic recovery of the smile harmony and patient satisfaction.
\end{abstract}

\section{KEYWORDS}

Dental esthetics; Tooth bleaching; Dental veneers; Composite resin.

\section{RESUMO}

Os autores apresentam um caso clínico completo envolvendo reabilitação funcional e estética da harmonia do sorriso de um paciente de 23 anos de idade através da associação de plastia gengival, clareamento dental e facetas pré-fabricadas de resina composta, ressaltando vantagens, limitações e a percepção do paciente. Após análise clínica, radiográfica, realizouse fotos intra/extra orais, obteve-se modelos de estudo em gesso e foram realizados o planejamento digital do sorriso e enceramento diagnóstico. Os procedimentos propostos foram aceitos e autorizados pelo paciente antes da sua realização. O tratamento realizado mostrou-se efetivo como uma alternativa prática e segura, com restabelecimento estético e satisfação do paciente.

\section{PALAVRAS-CHAVE}

Estética dental; Clareamento dental; Resina composta.

\section{INTRODUCTION}

Cmall and malpositioned teeth as well $\checkmark$ as inadequate mesiodistal relationship compromise the dental occlusion, golden proportions, and lead to the presence of diastema or crowding that may interfere with the aesthetics of the smile. This clinical situation may cause discomfort to the patient and brings the challenge of conservative aesthetic solution to dental professionals.

Restorative procedures with minimal dental preparation that employ adhesives, ceramics or state-of-the-art composite resins represent dental aesthetic approaches that 
improves patient's satisfaction. Examples may include ceramic laminate veneers or fragments as well as direct or indirect composite resin restorations [1-3].

Indirect ceramic restorations are more wear resistant than direct restorative materials. However, they require laboratory steps and are time-consuming, which may increase the treatment costs. Direct resin composite restorations require dentist skills and undergo polymeric deterioration overtime [2]. The indirect use of these composites is linked to the evolution of these materials. The improvement of dental composite properties enables dental mimetization and promotes the achievement of restorations with greater smoothness and wear resistance [4].

The introduction of dental veneers in anterior teeth dates back to 1937. Since the 1970s, they became popular among dentists due to the development of composites, adhesive systems and dental preparation protocols that supported dental restorations with greater preservation of the tooth structure [5].

Prefabricated composite resin veneers were introduced in the 1980s in a system called mastique (Dentsply/Caulk) composed of methyl methacrylate and large inorganic particles. However, due to the difficulties of adhesion and little chemical stability, this system was not efficient enough to overcome the challenges of the oral cavity [2].

A concept of prefabricated composite resin veneers has been reintroduced in 2011, through the system called Direct Venear (Edelweiss Dentistry, Hoerbranz, Austria), composed of nanohybrid resin with additional laser technology, which gives the veneers a hard and shiny surface, with texture similar to the natural dentition [5]. The current prefabricated veneers, such as the Componeer / Coltene system, have a technological development advance with significant improvements in their composition and degree of polymerization conversion [6].

This article aims to present a complete clinical case report of functional and aesthetic rehabilitation of the smile harmony of a 23-yearold male patient through periodontal plastic surgery, tooth bleaching and prefabricated composite resin veneers, emphasizing the advantages, limitations and patient's perceptions about the treatment.

\section{CASE REPORT}

A 23-year-old male patient reported dissatisfaction with the appearance of his smile. The clinical examination showed direct composite resin restorations with changes in color, shape, texture and brightness of the elements 13,12,11,21,22 and 23 (Figures 1 and 2).

Intra and extra oral photographs were taken. Digital smile design was performed through the software Power Point 2016 (Microsoft, Redmont, WA, Estados Unidos) in order to provide ideal dental dimensions and proportions as well as gingival contour. The treatment plan consisted in periodontal plastic surgery, tooth bleaching and tooth contouring and reshaping with prefabricated composite resin veneers. The patient accepted and signed the consent form regarding the proposed treatment.

The normality of the hematological examinations (hemogram, coagulogram and fasting glycemia) was checked. Gingivoplasty was performed in the region of element 11, which resulted in harmonious appearance of the gingival contour (Figure 3).

The tissue healing was observed and the composite resin restorations of the elements $13,12,11,21,22$ and 23 were removed with dental diamond burs 3080, 2135F and 3195FF (KG Sorensen, Cotia, SP, Brazil). The enamel was polished with Sof-Lex ${ }^{\mathrm{TM}}$ pop-on disks (3M, Maplewood, Minnesota, EUA) (Figure 4). 


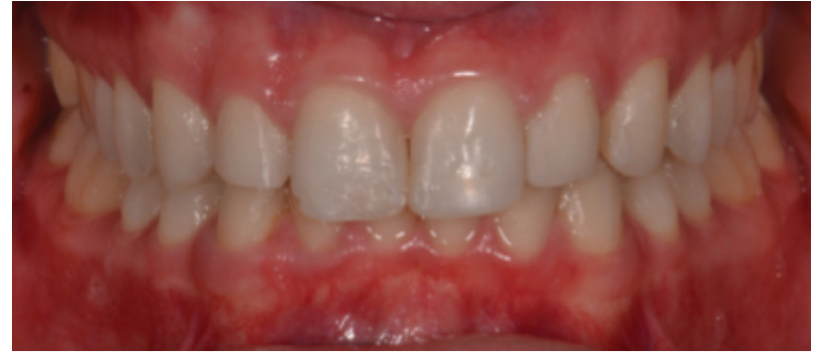

Figure 1 - Initial clinical aspect.

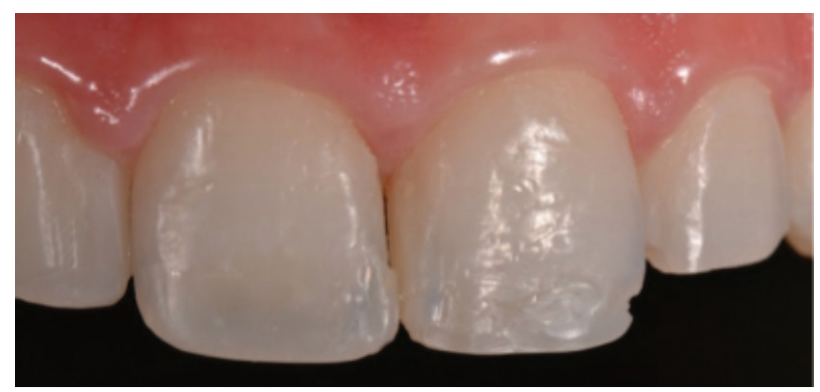

Figure 2 - Fractured restorations in the maxillary central incisors.

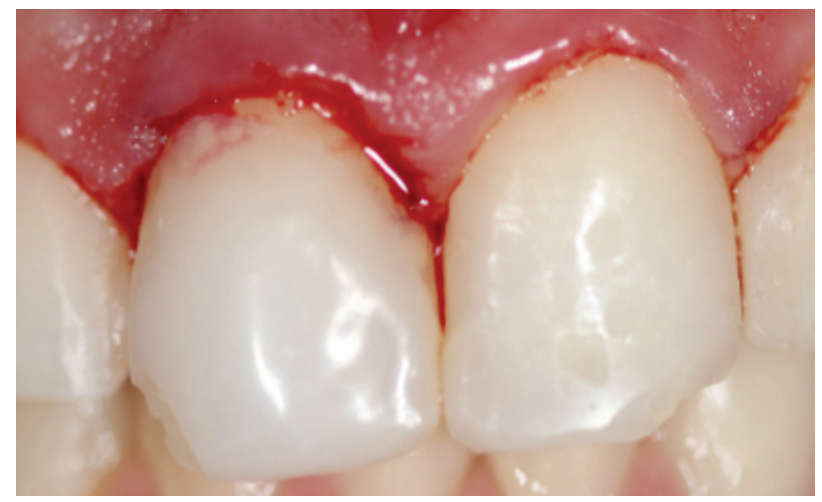

Figure 3 - Optimized gingival contour after the gingivoplasty.

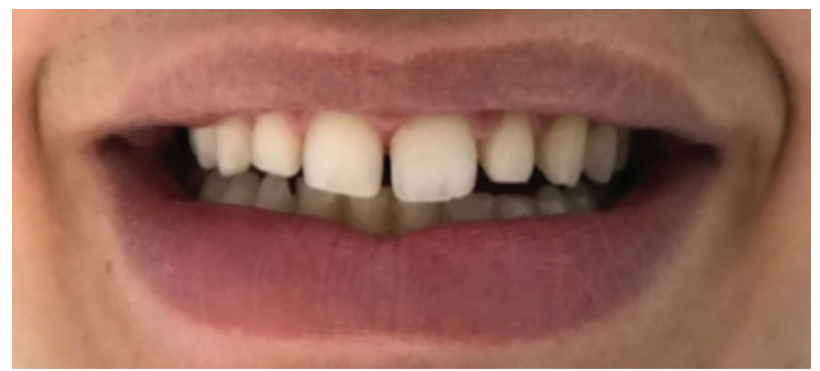

Figure 4 - Smile appearance after the removal of composite resin restorations.
At-home dental bleaching with 16\% carbamide peroxide gel (Whiteness perfect FGM, Joinville, SC, Brazil) was prescribed 04 hours a day, for 15 days, in order to improve the appearance and color uniformity of the teeth.

We proceeded with the placement of the prefabricated composite resin veneers. The Brilliant NG Componeer System (Coltene, Altstatten, Switzerland) was chosen given its cost-benefit ratio, practicality of cementation and favorable aesthetics results. The Componeer System consist of ultrathin composite resin shells $(0.3 \mathrm{~mm}$ cervical and $0.6 / 1.0 \mathrm{~mm}$ incisal) prefabricated in Brilliant NG composite resin (Coltene, Altstatten, Switzerland). The manufacturer recommends that the cementation of the prefabricated resin veneers should be performed with the same composite resin from which the veneer is fabricated, allowing the restoration to form a monoblock [7].

The large size of the prefabricated composite resin veneers of the Componeer System was selected through the Brilliant ${ }^{\mathrm{TM}}$ NG COMPONEER Contour Guide (Coltene, Altstatten, Switzerland), positioned on the teeth (Figure 5).

The prefabricated composite resin veneer color was selected with the BrilliantTM NG Shade Guide (Coltene, Altstatten, Switzerland). We opted for the "bleach" color for the veneer and dentin A1/B1 for the resinous material used for cementation. The placement of the veneers was performed following the protocol:

A - Preparation of the pre-fabricated composite resin veneer:

1 - Venner's adjustments with higher abrasiveness Sof-Lex ${ }^{\mathrm{TM}}$ pop-on discs (3M, Maplewood, Minnesota, EUA).

2 - Decontamination of the venner's surface with alcohol $70^{\circ}$.

3 - Application of the adhesive system One coat Bond SL (Coltene, Altstatten, 
Switzerland) on the veneer's inner side and removal of excess with an air jet. The adhesive system was not photoactivated.

B - Tooth Preparation (elements 13, 12, $11,21,22$, and 23):

1 - Isolation of the operative field (labial retractor, cotton rolls and saliva ejector).

2 - Prophylaxis with pumice and. After cleaning of tooth surface, teeth were washed with water and air dried.

3 - Etching with 37\% phosphoric acid (Magic Acid - Altstatten, Switzerland) for 30 seconds. The teeth were washed with water for 60 seconds and dried with air-jet (Figure 6).

Application of the adhesive One Coat Bond SL (Coltene, Altstatten, Switzerland) on the conditioned enamel for 20 seconds and removal of the excesses with an air jet (Figures 7 and 8).

After the preparation of the adhesive surfaces, a single increment of Brilliant NG composite resin (dentin A1/B1) was applied to the inner side of the veneers. The veneers were placed on the teeth and pressed with a silicone spatula (TDV, Pomerode, Santa Catarina, Brazil) in order to extravasate the excess of composite resin (Figure 9). For excesses removal, a composite filling instrument and brush were used on the buccal surface and polyester strips on the distal and mesial surfaces (Figure 10). The polymerization was carried out with Radiicall LED curing light (SDI, Bayswater, Victoria, Australia).

The texturing and individualization of the veneers were performed after seven days. Polishing discs (3M, Maplewood, Minnesota, EUA) and rubber polishing points were used. Figures 11 and 12 show the results accomplished in this clinical case report.

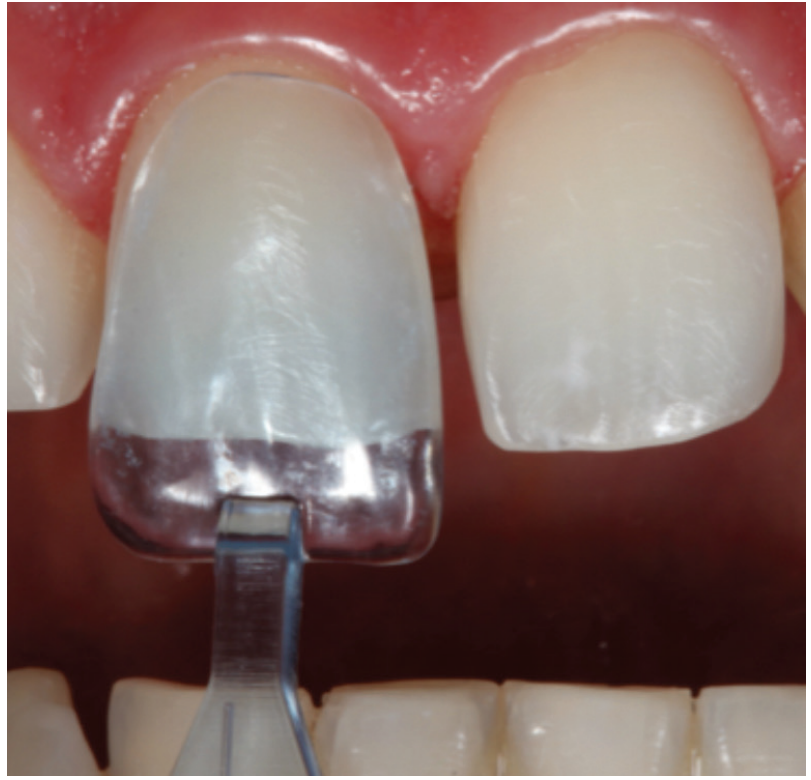

Figure 5 - Selection of the prefabricated composite resin veneer with the contour guide.

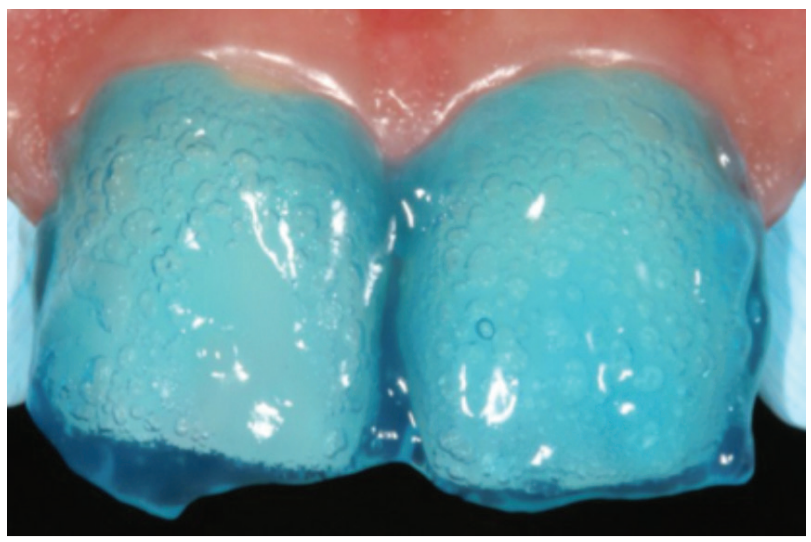

Figure 6 - 37\% phosphoric acid etching on enamel.

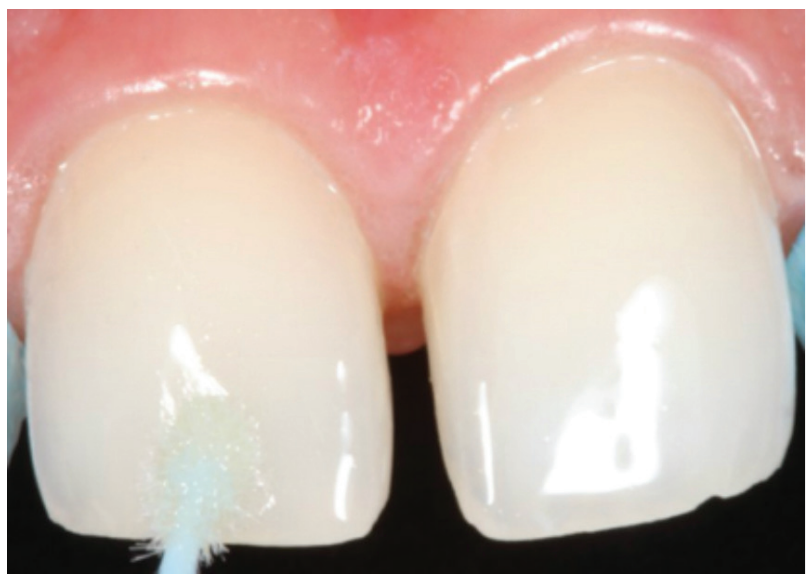

Figure 7 - Application of the adhesive system. 


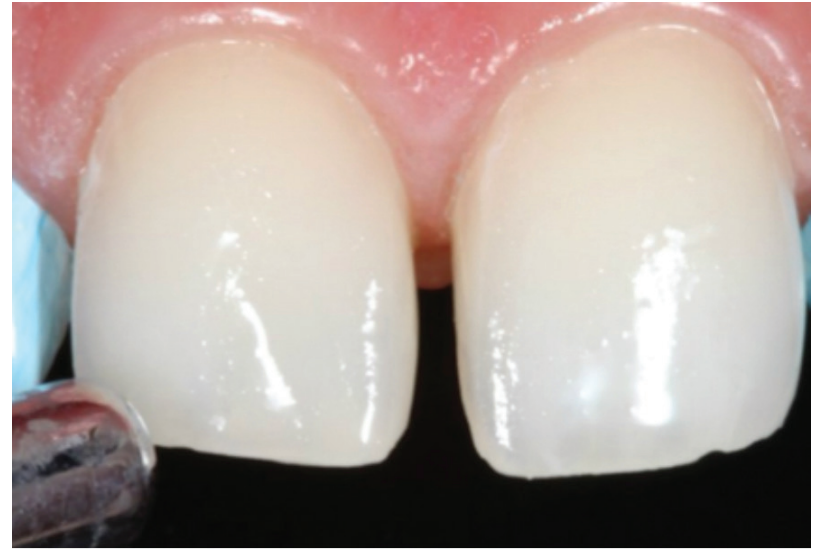

Figure 8 - Removal of the excesses of the adhesive with air jet.

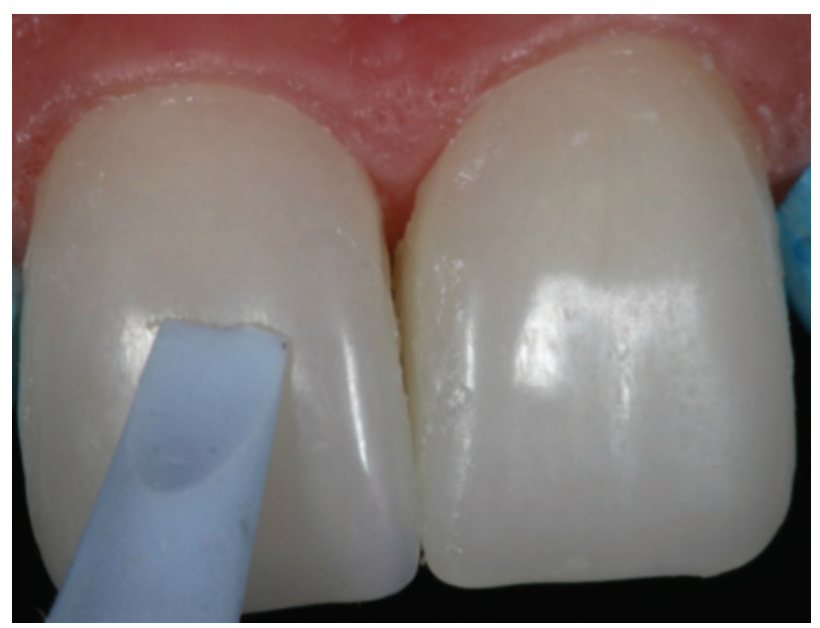

Figure 9 - Placement of the veneers on the teeth with a silicone spatula.

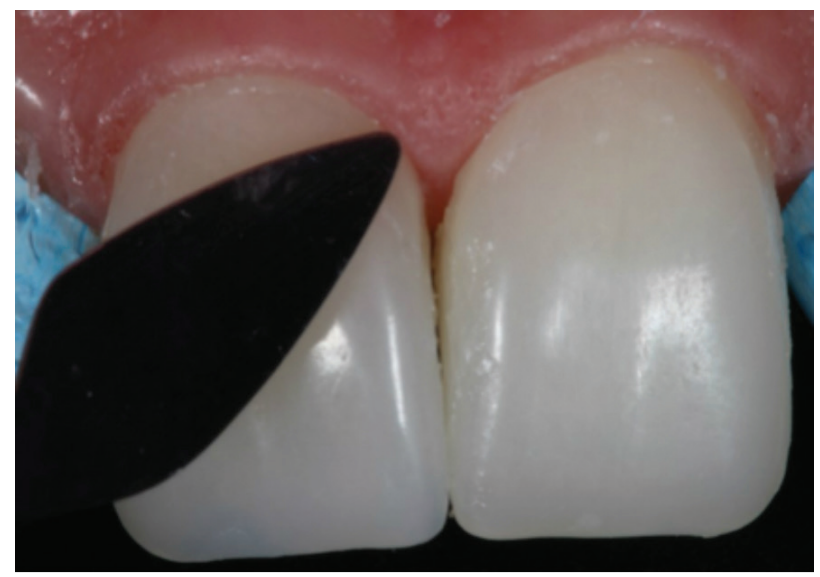

Figure 10 - Removal of the excess of composite resin.

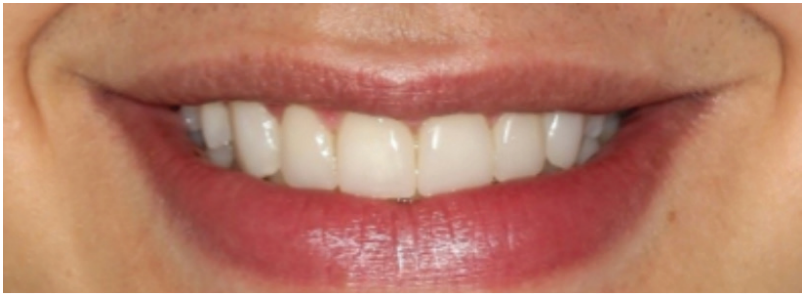

Figure 11 - Final clinical aspect of the smile.

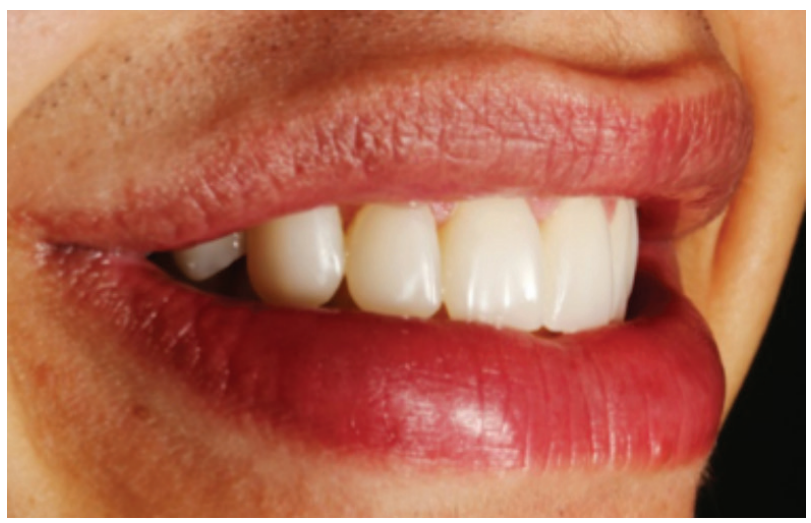

Figure 11 - Side view of the final patient smile.

\section{DISCUSSION}

Direct composite resin restorations present some limitations such as the difficulties of color match and surface polishing and finishing given that these procedures depend on the operator's skills. The maintenance of favorable aesthetics results in direct veneers is influenced by the polymerization, polymer deterioration, diet and patient's care and deleterious oral habits [2,8-10]. On the other hand, the prefabricated composite resin veneers are pre-polymerized with greater surface hardness and degradation resistance, which may increase the survival rate and longevity of the composite restorations [11].

Prefabricated composite resin veneers present good aesthetic results and practical placement technique. A skilled professional is able to improve the pre-set sizes to any tooth shape and size. Dental preparation may not be necessary in specific situations and with the use of the composite resin for cementation, is possible to align easily the veneer on the teeth surface. If the 
operator wants to obtain individualized veneers, finishing and polishing discs may be used $[2,11]$.

The prefabricated composite resins employed in this clinical case report are composed of a nanohybrid resin composite with high fraction of filler particles (80\% weight and 65\% volume), radiopaque (radiopacity of $2 \mathrm{mmAl}$ ), and enamel characteristics that give it a natural appearance similar to the dental structure. The organic matrix is composed of BisGMA, Bis-EMA, TEGDMA and EDAB and has camphorquinone for the initiation of the polymerization. The charge Particles were not stated by the manufacturer and average particle size was $0.6 \mu \mathrm{m}$ with particle size variation ranging from 0.01 to $2.5 \mu \mathrm{m}$. The modulus of elasticity ( $9 \mathrm{GPa}$ ) is close the dental structure and the compressive strength (392 MPa) makes this material to better able withstand compression. The water solubility $\left(0.9 \mu \mathrm{g} / \mathrm{mm}^{3}\right)$ and water absorption $\left(16 \mu \mathrm{g} / \mathrm{mm}^{3}\right)$ may indicate minimal degradation over time [12].

The inner side of the prefabricated composite resins is micro-retentive and does not require prior acid etching. The manufacturer recommends the cementation with Brillant NG composite resin (Coltene, Altstatten, Switzerland). This composite with prepolymerized particles, reduced to nanometric size, provides superior mechanical properties and excellent handling given that it is non-sticky, does not lose shape before polymerization, exhibits minor polymerization shrinkage, and presents easy and fast polishing and finishing as well as good surface gloss [12].

The photoactivation of composite resin used for cement should start at the palatal surface, with an ultraled, for 40 seconds, followed later by photoactivation for the same time at the buccal surface. Retraction technique before cementation was not needed given that the prefabricated composite resin were placed above the gingival margin.
Good polymer conversion of the composite resin used for cementation will aid in color stability. Moreover, the oral hygiene and patient's diet may have effect on the color stability of the prefabricated composite resin veneers. In spite of its potential as dental restorative alternative, the use of prefabricated composite resin veneers requires controlled, long-term clinical studies [2].

\section{CONCLUSION}

The prefabricated composite resin veneer of the Componeer System proved to be an effective, practical and safe restorative treatment that resulted in aesthetic recovery of the smile harmony and patient satisfaction.

\section{REFERENCES}

1. Conceição EM, et al. Restauração de resina composta direta em dentes anteriores. In:CONCEIÇÃOEN. etal. Dentística: Saúde e Estética. Porto Alegre; Artmed:2007.

2. Chain MC, Alexandre P.Facetas estéticas pré-fabricadas como procedimento restaurador - um caso clínico. Full DentSci. 2014;5(18):338-44.

3. Magne P,Magne M, Belser UC. Adhesive restorations, centric relation, and the Dahl principle: minimally invasive approaches to localized anterior tooth erosion. Eur JEsthet Dent. 2007 Autumn;2(3):260-73.

4. Mendonça AAM, Rocha DM. Facetas pré-fabricadas em resina composta uma realidade clínica: relato de caso clínico. Universidade Federal de Sergipe. २०16.

5. Dietschi D, Devigus. A. Prefabricated composite veneers: historical perspectives, indications and clinical application. Eur J EsthetDent. 2011 Summer;6(2):178-87.

6. Touati B, Aidan N. Second generation laboratory composite resin for indirect restoration. JEsthet Dent. 1997;9(3):108-18.

7. Gomes G, Perdigão J. Prefabricated composite resin veneers: a clinical review. JEsthet Restor Dent. 2014 Sep-0ct;26(5):302-13. doi: 10.1111/jerd.12114. Epub 2014 Jun 18.

8. Chain MC. Materiais dentários. São Paulo:Artes Médicas;2013.

9. Gresnig MM, Kalk W, Ozcan M. Randomized controlled split-mouth clinical trial of direct laminate veneers with two micro-hybrid resin composites. JDent. 2012Sep;40(9):766-75. doi:10.1016/j.jdent.2012.05.010. Epub2012 Jun2.

10. Gresnigt MM, Kalk W, Ozcan M. Randomized clinical trial of indirect resin composite and ceramic veneers: up to 3-year follow-up. J Adhes Dent. 2013 Apr;15(2):181-90. doi:10.3290/j.jad.a28883.

11. Souza EM, Silva e Souza JRMH, Lopes, FAM, Osternack FHR. Facetas estéticas indiretas em porcelana. JBD. 2002;1(3):256-62.

12. Brilliant NG Componeer. Rio de Janeiro: Vigodent. Package Leaflets. Available at: «Em:http://www.coltene.com.br/wpcontent/uploads/2015/06/ Instru\%C3\%A7\%C3\%B5es-de-uso7.pdf. 


\section{Claudio Heliomar Vicente da Silva}

(Corresponding address)

Rua Jorge Couceiro da Costa Eiras, 443, Apto 2403, Boa

Viagem. Recife - PE - Brasil, zip code: 51021-300.

Date submitted: 2017 Nov 19

Email: claudio_rec@hotmail.com

Accept submission: 2018 Jan 12 